\title{
O Uso de Pedoindicadores no Processo de Avaliação da Restauração Florestal de Áreas Degradadas do Município de Santo Antônio de Pádua-RJ
}

\author{
The Use of Pedoindicators in the Evaluation Process of Forest Restoration of \\ Degraded Areas in the Municipality of Santo Antônio de Pádua-RJ
}

El Uso de Pedoindicadores en el Proceso de Evaluación de la Restauración Forestal de Áreas Degradadas en el Municipio de Santo Antônio de Pádua-RJ

\author{
Cássia Barreto Brandão ${ }^{1}$ \\ https://orcid.org/0000-0003-1576-2545 \\ Antônio Soares da Silva ${ }^{2}$ \\ https://orcid.org/0000-0003-3537-5438
}

\begin{abstract}
RESUMO: O presente estudo visa avaliar o uso de pedoindicadores no processo de restauração florestal de áreas degradadas do município de Santo Antônio de Pádua-RJ. Para tanto, foram utilizados dados de fertilidade, análise de lâminas micromorfológicas e contagem total de bactérias e fungos em áreas distintas de degradação, restauração (área restaurada de 15 anos e de restauração recente) e de referência. Os resultados demonstraram que a área de restauração recente obteve os melhores indicadores de fertilidade quando comparada ao setor de restauração mais antiga em virtude dos processos de remoção de nutrientes para jusante $A$ área controle $\mathrm{e}$ a área desmatada apresentaram os valores extremos dos parâmetros químicos analisados, comportando-se como referência de valores favoráveis e limitantes do substrato. A análise micromorfológica, assim como a contagem de bactérias e fungos, se constituíram como análises que forneceram suporte às demais interpretações das condições do substrato, pois apresentaram por vezes associações com a fertilidade dos solos analisados, permitindoconcluir que a rizosfera das áreas em processo de restauração florestal ainda não ésimilarà área controle.
\end{abstract}

PALAVRAS-CHAVE: Solos. Indicadores de qualidade. Conservação.

ABSTRACT: The present study aims to evaluate the use of pedoindicators in the forest restoration process of degraded areas in the municipality of Santo Antônio de Padua-RJ. For this purpose, soil fertility data, analysis of micromorphologic slides and total bacterial and fungal counts in distinct areas of degradation, restoration (15-year restored area and recent restoration) and reference were used.

\footnotetext{
${ }^{1}$ Possui doutorado em Geografia pela Universidade do Estado do Rio de Janeiro. Professora Adjunta de Pedologia e Geomorfologia da Universidade do Estado do Rio de Janeiro. E-mail: cassiabbgeo@gmail.com.

${ }_{2}^{2}$ Possui doutorado em Geologia pela Universidade Federal do Rio de Janeiro (2006). Professor Adjunto da Universidade do Estado do Rio de Janeiro. E-mail: asoares.uerj@gmail.com.
} 
The results showed that the recent restoration area obtained the best fertility indicators when compared to the oldest restoration sector due to the nutrient leaching processesfor downstream. The control area and the deforested area presented the extreme values of the analyzed chemical parameters, behaving as a reference for favorable and limiting substrate values. The micromorphological analysis, as well as the counting of bacteria and fungi were constituted as analyses that provided support to other interpretations of the fertility, since they sometimes presented associations with the characteristics of the sorbent complex of the analyzed soils, allowing the conclusion that the rhizosphere of the areas in the process of forest restoration are not yet similar to the reference area.

KEYWORDS: Soils. Quality indicators. Conservation.

RESUMEN: El presente estudio tiene por objeto evaluar el uso de pedoindicadores en el proceso de restauración forestal de áreas degradadas en el municipio de Santo Antônio de Pádua-RJ. Para este fin se utilizaron datos sobre la fertilidad, el análisis micromorfológicos y los recuentos totales de bacterias y hongos en distintas áreas de degradación, restauración (área restaurada de 15 años y de restauración reciente) y de referencia. Los resultados mostraron que la área de restauración reciente obtuvo los mejores indicadores de fertilidad en comparación con la área de restauración antigua debido a la eliminación de nutrientes em la pediente. El área de control y el área deforestada presentaron los valores extremos de los parámetros químicos analizados, comportándose como referencia para valores de sustrato favorables y limitantes. Los análisis micromorfológicos, así como el recuento totales de bacterias y hongos se constituyeron en análisis que sirvieron de apoyo a las demás interpretaciones de las condiciones del sustrato, ya que en ocasiones presentaron asociaciones con las características de la fertilidad de los suelos analizados, lo que permitió concluir que la rizosfera de las áreas en proceso de restauración forestal no son todavía similares al área de referencia.

PALABRAS CLAVE: Suelos. Indicadores de calidad. Conservación.

\section{INTRODUÇÃO}

O restabelecimento de comunidades vegetais nativas é uma das formas mais utilizadas para restauraçãode áreas degradadas pela mineração, sendo necessário,porém, analisar os resultados de formasistemáticanos primeiros anos após a implementação das medidas de restauração (ALMEIDA; SANCHEZ, 2015). A restauração ecológica pode ser entendida como o "[...] processo de assistir à recuperação de um ecossistema que foi degradado, perturbado ou destruído" (SOCIETY FOR ECOLOGICAL RESTORATION INTERNATIONAL SCIENCE \& POLICY WORKING GROUP, 2004, p. 1), assim como a avaliação pode ser entendida como a análise de indicadores ou variáveis ambientais da área restaurada.

Entre os ecossistemas brasileiros, a Mata Atlântica foi um dos que mais sofreu, e vem sofrendo, intensos e persistentes processos de degradação e fragmentação florestal, restando apenas $15,2 \%$ da sua cobertura original, considerando os fragmentos com área maior que três hectares. Neste sentido, esses fragmentos florestais remanescentes são 
importantes para a biodiversidade e para a estabilidade da paisagem (FUNDAÇÃO SOS MATA ATLÂNTICA, 2019).

Por meio do estabelecimento de indicadores é possível avaliar o progresso da restauraçãoflorestal, sendo utilizado para tal finalidade estimativas das condições físicas e estruturais do meio, assim como os aspectos relacionados àbiodiversidade e aos processos ecológicos. O uso de indicadores do solo selecionados por este estudo é de sumaimportância, uma vez que,as características edáficas se modificam ao longo do tempo como resultado das medidas de restauração. De acordo com Brancalion, Gandolfi e Rodrigues (2009), levantamentos de solos para análise química e física podem ser bastante úteis ao processo de avaliação da restauração de áreas degradadas, bem como, a ciclagem de nutrientes e a meso e macrofauna edáfica.

Segundo Brancalion, Gandolfi e Rodrigues (2015, p. 17) “[...] a restauração florestal é uma intervenção humana intencional em ecossistemas alterados para desencadear, facilitar ou acelerar o processo natural de sucessão ecológica". Contudo, a restauração florestal é a criação de uma nova condição semelhante a uma área florestal de referência, sendo que esta condição jamais será igual ao ecossistema original antes de ser degradado.

Mediante o uso de pedoindicadores no monitoramento da restauração florestal é possível comparar os ecossistemas em restauração com os ecossistemas atribuídos como de referência para acompanhar as diferentes etapas da evolução da restauração florestal (RODRIGUES, 2013).

Essas informações são essenciais na avaliação da restauração ambiental, uma vez que o solo é o substrato que fornece às plantas e organismos vivos os nutrientes necessários à sobrevivência. Neste contexto, este estudo se baseou na análisede pedoindicadores, como a análise da organização interna dos constituintes do solo (micromorfologia), contagem de bactérias e fungos e em parâmetros da fertilidade do solo. Foram selecionadas quatro áreas com diferentes tipos de cobertura do solo em zona de mineração do município de Santo Antônio de Pádua- RJ, de modo a associar e comparar as evoluções entre asáreas desmatada, restauradade 15 anos e de três anos com a área controle/referência (fragmento utilizado como referência para região em estudo e caracterizada por apresentar mata nativa de Mata Atlântica em topo de morro e em estágio médio de sucessão ecológica).

\section{LOCALIZAÇÃO DA ÁREA DE ESTUDO}

O município de Santo Antônio de Pádua está localizado na Região Noroeste do Estado do Rio de Janeiro, sendo banhado pelos rios Paraíba do Sul, Pomba e Pirapetinga. Sua área territorial é de 603 quilômetros quadradose sua população é de 39.750 habitantes, 
de acordo com a contagem da população pelo IBGE (2010). Em associação ao projeto de recuperação de áreas degradadas iniciado em 2012 no município, este presente estudo foi realizado nas proximidades da pedreira Quatro Irmãos.

No município de Santo Antônio de Pádua encontram-se alinhamentos serranos que abrigam jazidas minerais e que ao longo das últimas décadas têm sido utilizadas para extração e beneficiamento de rochas (SILVA, 2011; SILVA; MARGUERON, 2002). Tal cadeia produtiva tem impulsionado a economia da região, gerando também o aumento dos problemas ambientais decorrentes da atividade (BRANDÃO et al., 2016). Tal caracterização das atividades econômicas da região torna-se importante uma vez que tais atividades possuem um impacto direto sobre a vegetação e o tipo de cobertura do solo.

Assim sendo, segundo Brum (2000) os efeitos da mineração se fazem sentir sobre o meio físico da região. São efeitos que afetam a paisagem (desaparecimento de morros), o solo (remoção, decapagem e aterro), a vegetação (desflorestamento) e as alterações das condições microclimáticas com tendência ao favorecimento da seca. A maior parte da região é dominada por colinas e morros baixos, apresentando em geral Argissolos VermelhoAmarelo distrófico e Argissolo Vermelho eutrófico (DANTAS et al., 2001).

Segundo Brasil e Silva (2013) o município se encontra com menos de $14 \%$ de sua cobertura original. Tal cenário é justificado pela devastação da Mata Atlântica para a implantação da monocultura cafeeira no final do século XIX, por pastagens subaproveitadas e pelo atual desmatamento nos maciços montanhosos e nas zonas dos alinhamentos serranos (LAMEGO, 1963).

A região de Santo Antônio de Pádua está sob o domínio da Mata Atlântica, caracterizada como floresta estacional semidecidual que é condicionada pela dupla estacionalidade climática: uma estação com chuvas intensas de verão, seguidas por um período seco durante o inverno. As matas remanescentes que cobrem algumas áreas da região são constituídas, na maioria, por formações secundárias que se desenvolvem onde a floresta foi derrubada (IBGE, 1977). No caso específico do município de Santo Antônio de Pádua a cobertura arbórea é muito fragmentada e concentrada em topo de morro e em serras (BRASIL; SILVA, 2013). Notadamente nos topos de alguns morros, há ocorrência do estágio médio de sucessão, que em linhas gerais é caracterizado pela presença de fisionomia arbórea predominando sobre a herbácea com ocorrência de maior número de epífitas, serapilheira e sub-bosques. 


\section{MATERIAIS E MÉTODOS - ANÁLISE DE PEDOINDICADORES}

As análises dos pedoindicadores ocorreram no ano de 2015 através de trabalhos de campo realizados na Pedreira Quatro Irmãos (figura 1). As áreas analisadas foram respectivamente: área restaurada de 15 anos (R15); área desmatada (DS); área restaurada de três anos (R03) e área controle com floresta nativa (em estágio médio de sucessão) em topo de morro (CT).

Figura 1 - Mapa de pontos de monitoramento

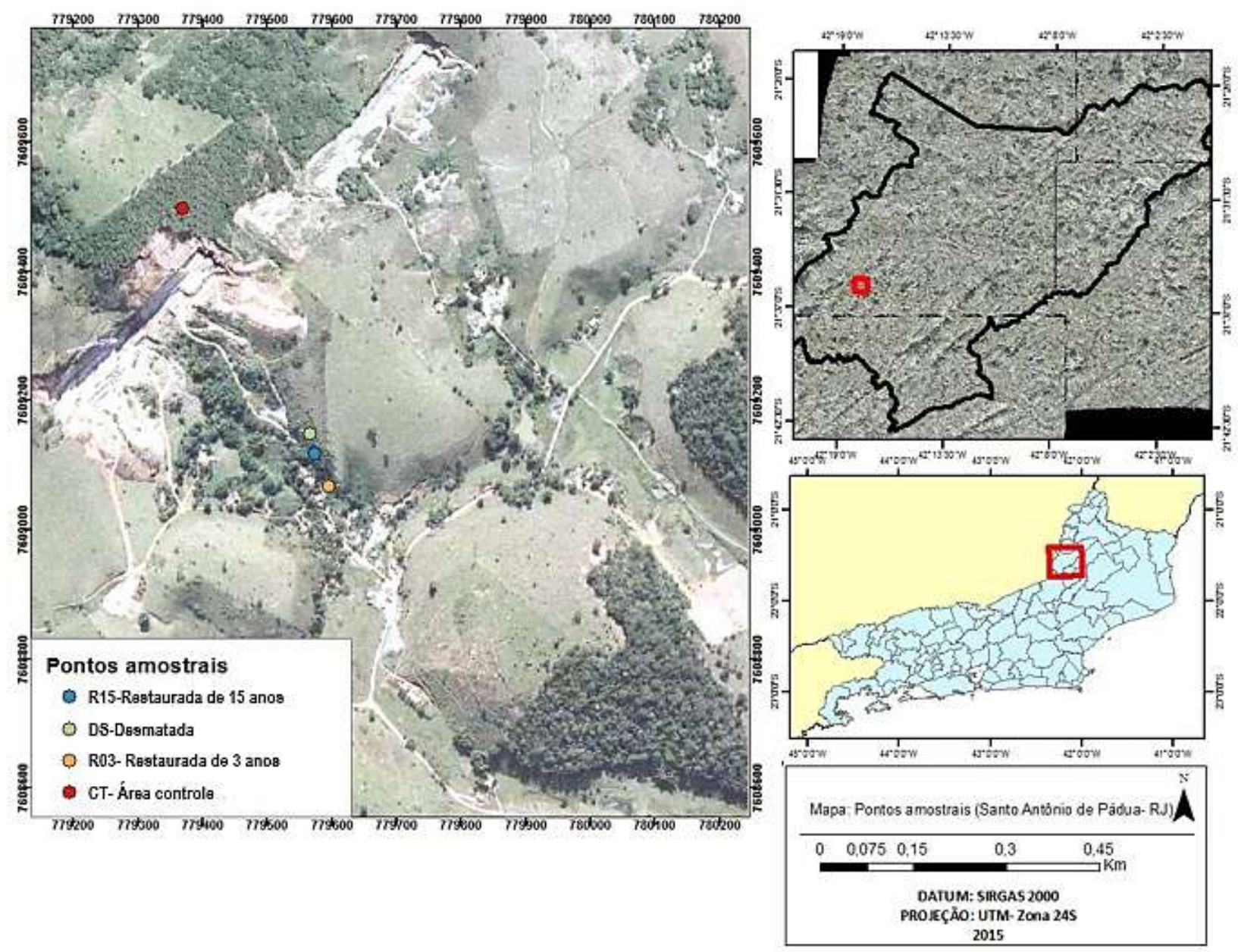

Fonte: elaborada pelos autores.

Com o objetivo de obter indicadores ambientais das respectivas áreas estudadas, foram realizadas análises de micromorfologia de solos, fertilidade de rotina (complexo sortivo) e contagem de bactérias e fungos nas quatro áreas (figura 2) monitoradas durante 0 projeto de recuperação e reabilitação de áreas degradadas por mineração na zona rural de Santo Antônio de Pádua- RJ que teve início no ano de 2012. Os mapeamentos realizados neste estudo foram desenvolvidos no programa ArcGIS 10.3. 
Figura 2 - Áreas de monitoramento

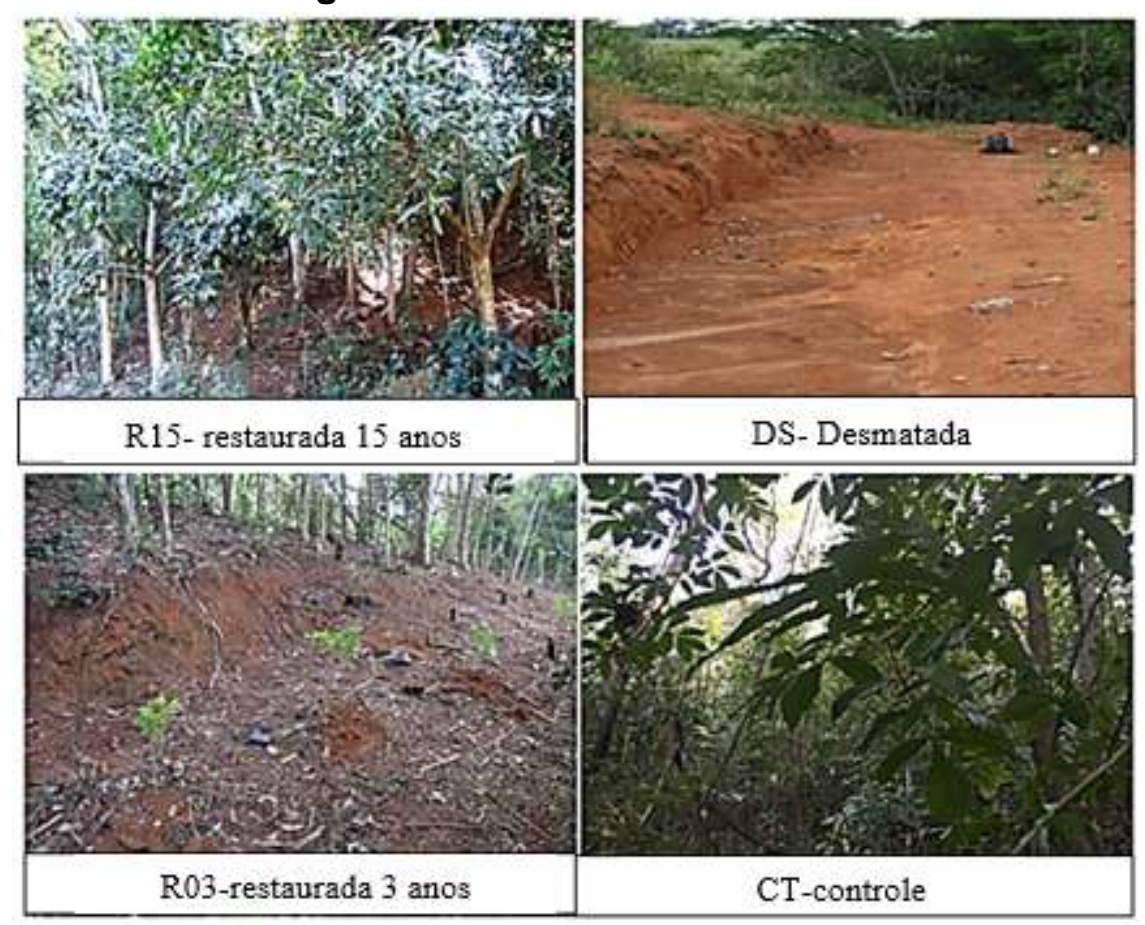

Fonte: elaborada pelos autores.

As análises de fertilidade bem como a quantificação de bactérias e fungos totais foram realizadas pelo laboratório da ESALQ-USP (Piracicaba-SP), sendo o último realizado pelo método de plaqueamento por gotas proposto por Jahnel, Cardoso e Dias (1999). Todas as amostras correspondem aos horizontes superficiais (20 centímetros) de Argissolo VermelhoAmarelo, com exceção da área desmatada (DS), que corresponde ao horizonte B exposto, uma vez que o horizonte $A$ foi removido pela atividade mineradora. O perfil topográfico da área de estudo pode ser observado através da figura 3.

Figura 3 - Perfil Topográfico das áreas monitoradas

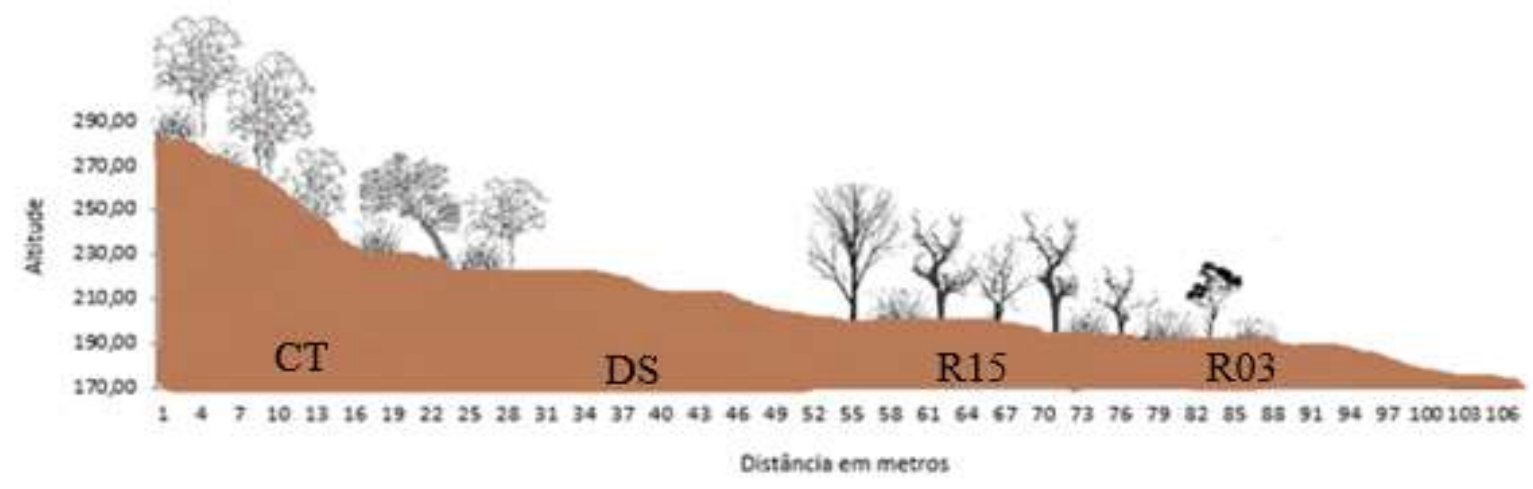

Fonte: elaborada pelos autores. 
A análise micromorfológica dos solos corresponde a uma técnica de observação morfológica em escala micrométrica. Para a realização desta técnica foram coletas amostras de solos com estrutura indeformadas em caixas de cartolina (12 cm x $7 \mathrm{~cm} \times 4 \mathrm{~cm}$ ). Junto à coleta registrou-se a orientação e a profundidade $(5 \mathrm{~cm})$ das amostras, sendo que posteriormente as amostras foram revestidas em filme plástico para proteção. No laboratório as amostras foram secas em estufa a $40^{\circ} \mathrm{C}$ para retirada de toda água e posterior troca por acetona. Após a substituição da água por acetona, as amostras foram impregnadas com resina com auxílio de um dessecador associado a uma bomba de vácuo (figura 4). Após esta etapa, com as amostras já endurecidas, foram realizados o corte e a laminação das amostras nos laboratórios de Geografia e Geologia da Universidade do Estado do Rio de Janeiro. Todo procedimento metodológico da coleta de monólitos para micromorfologia foram baseados no manual de métodos de análise de solos de Teixeira et al. (2017).

Figura 4 - Etapas de elaboração de lâminas micromorfológicas
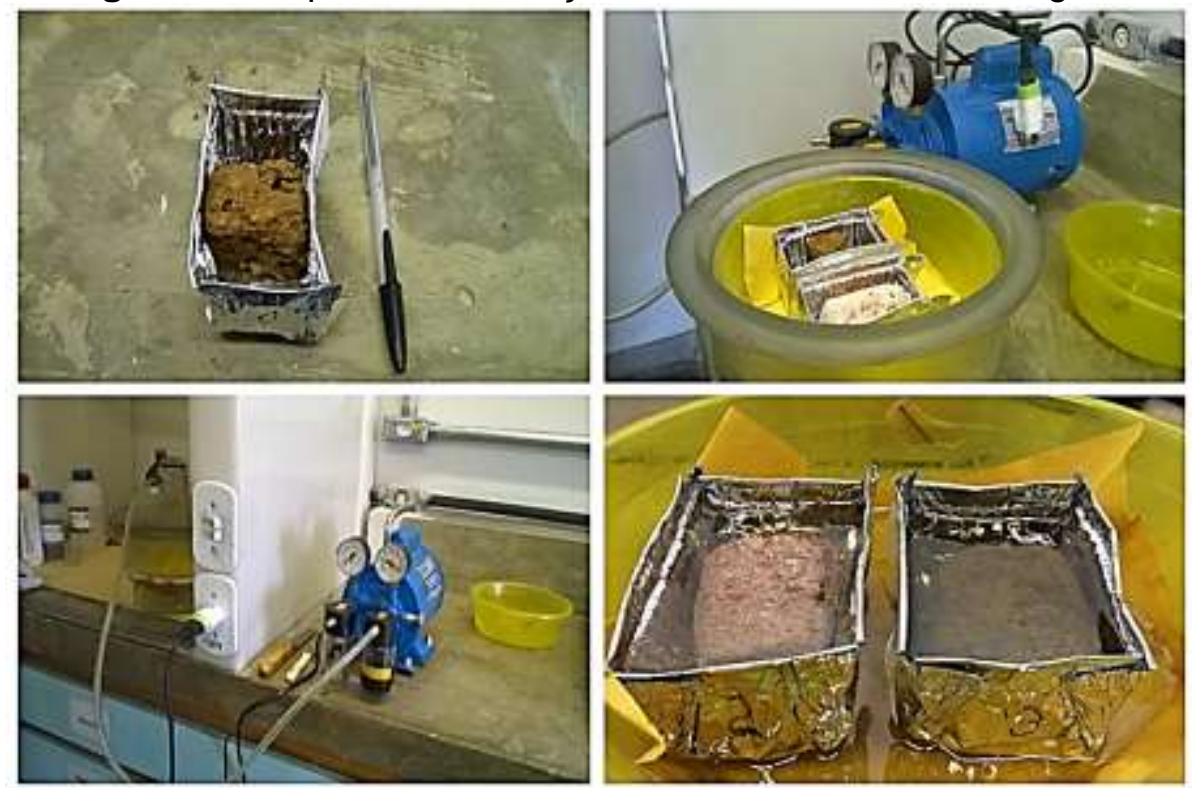

Fonte: Elaborada pelos autores. Legenda: no sentido horário, iniciando na parte superior esquerda: monólito de solo em caixa de alumínio pronto para ser impregnado; amostra colocada em dessecador em vácuo de baixa pressão; impregnação em curso com resina; e amostras endurecidas após duas semanas, prontas para corte e laminação.

Foram confeccionadas lâminas para R15, R03 e CT, sendo que a análise micromorfológica de DS não foi possível de ser realizada em virtude do material friável que impediu a obtenção de uma amostra indeformada. As amostras corresponderam a horizontes superficiais $(5 \mathrm{~cm})$ tendo em vista a maior concentração da atividade biológica em superfície. As lâminas foram interpretadas de acordo com as metodologias de classificação de Brewer (1976) e Bullock et al. (1985), sendo que as descrições e interpretações das lâminas foram realizadas em microscópio petrográfico do Museu Nacional-RJ. 


\section{RESULTADOS}

\section{Indicadores Químicos do solo}

A tabela 1 demonstra os elementos analisados nas quatro áreas de estudo. Todas as áreas analisadas apresentaram pH ácido, o que, de acordo com Lepsch (2011) é comum para solos tropicais devido ao intenso processo de lixiviação. A área restaurada $(R 15)$ e a desmatada apresentaram acidez elevada e a área R03 e a de controle apresentaram acidez média de acordo com os parâmetros estabelecidos por Alvarez (1999) e por Raij (2017). Estes resultados estão de acordo com dados obtidos para a região por Costa e Silva (2015), Sattler et al. (2017) e Seliger et al. (2018). Assim sendo, as áreas sem cobertura vegetal e as áreas de maior declividade estão mais sujeitas a remoção das bases, fato esse observado na área desmatada e na área reflorestada (R15). Estudos hidrogeoquímicos realizados por Silva (2006) mostram que existe uma variabilidade espacial entre a composição da água do topo do solo em relação a nutrientes na encosta, sendo a disponibilidade de nutrientes mais efetiva nas áreas adjacentes aos fundos de vale do que nas maiores declividades. Isso ocorre porque as áreas de maior declividade são muito mais suscetíveis à erosão e, consequentemente, perdem nutrientes adsorvidos aos coloides do solo. Estes mecanismos explicam, principalmente, a variação no valor de saturação por bases entre as áreas restauradas (R15 e R03).

Tabela 1 - Complexo sortivo do solo

\begin{tabular}{|c|c|c|c|c|c|}
\hline DETERMINAÇÕES & UNIDADES & & & & \\
\hline & & $\begin{array}{l}\text { Área restaurada } \\
\text { (R15) }\end{array}$ & $\begin{array}{c}\text { Área } \\
\text { desmatada } \\
\text { (DS) }\end{array}$ & $\begin{array}{l}\text { Área restaurada } \\
\text { (R03) }\end{array}$ & $\begin{array}{l}\text { Área } \\
\text { controle } \\
\text { (CT) }\end{array}$ \\
\hline pH_H2O & & 4,6 & 4,6 & 5 & 5,4 \\
\hline P Mehlich 1 & $\mathrm{mg} \cdot \mathrm{dm}^{-3}$ & 7,3 & 3,3 & 8.1 & 8,6 \\
\hline $\mathrm{K}$ & $\mathrm{mg} \cdot \mathrm{dm}^{-3}$ & 143 & 47 & 141 & 260 \\
\hline Ca KCl $1 \mathrm{~mol}^{-\mathrm{L}^{-1}}$ & cmolc. $\mathrm{dm}^{-3}$ & 0,7 & 0,2 & 1,6 & 4,7 \\
\hline Mg KCl $1 \mathrm{~mol}^{-\mathrm{L}^{-1}}$ & cmolc. $\mathrm{dm}^{-3}$ & 0,5 & 0,2 & 0,8 & 1,4 \\
\hline Al KCl $1 \mathrm{~mol}^{-\mathrm{L}^{-1}}$ & cmolc. $\mathrm{dm}^{-3}$ & 0,9 & 1,1 & 0,5 & 0,3 \\
\hline H+Al Acetato de Cálcio & cmolc. $\mathrm{dm}^{-3}$ & 7,7 & 5,9 & 5,2 & 4.1 \\
\hline $\mathbf{s}$ & cmolc. $\mathrm{dm}^{-3}$ & 1,6 & 0,6 & 2,7 & 6,8 \\
\hline CTC & cmolc. $\mathrm{dm}^{-3}$ & 9,3 & 6,5 & 8 & 11 \\
\hline $\mathbf{V}$ & $\%$ & 17,9 & 9,7 & 34,3 & 61,3 \\
\hline M & $\%$ & 35,4 & 66,1 & 15,5 & 4,2 \\
\hline MOS & g.dm.3 & 29,5 & 15,6 & 41,2 & 53.1 \\
\hline
\end{tabular}

Fonte: elaborada pelos autores. Legenda: MOS- Matéria orgânica do solo; S- Soma das bases; CTC- Capacidade de troca catiônica; V-Saturação por bases; m- saturação por Alumínio, H+Al acidez potencial; K-potássio; P-fósforo; Ca- Cálcio; Mg- Magnésio; Al- Alumínio; pH- potencial hidrogeniônico. 
$\mathrm{O} \mathrm{pH}$ fornece indícios das condições químicas gerais do meio. Solos com acidez elevada (baixos valores de $\mathrm{pH}$ ) geralmente apresentam: pobreza em bases (cálcio e magnésio principalmente); elevado teor de alumínio tóxico; excesso de manganês; e deficiência de alguns micronutrientes. Os processos de lixiviação em conjunto com o intemperismo químico são responsáveis por remover os cátions de caráter básico do complexo de troca dos solos e por acumular cátions de natureza ácida como o $\mathrm{Al}$ e $\circ \mathrm{H}$. Segundo Malavolta (1993) um meio ácido é desfavorável à atividade microbiana e consequentemente é desfavorável à decomposição da MOS e à fixação do nitrogênio. Os valores mais próximos à neutralidade são os que mais favorecem no aumento da velocidade da decomposição da matéria orgânica. Para as plantas a faixa ideal de $\mathrm{pH}$ situa-se entre 6,0 - 6,5, que é a faixa na qual os nutrientes encontram-se mais disponíveis para as raízes das plantas, sendo neste sentido o resultado das áreas R03 e CT os que mais se aproximaram dessa faixa ideal.

A acidez potencial $\left(\mathrm{H}^{+}+\mathrm{Al}^{3+}\right)$ corresponde ao somatório de acidez trocável e acidez não trocável que se encontram adsorvidas (ligadas à CTC do solo). A acidez potencial na maioria das áreas se apresentou como muito elevada, com exceção deCT que obteve índice médio de 4,1 cmolc. dm $^{-3}$ de acidez potencial.

Os maiores valores de matéria orgânica foram encontrados respectivamente na área controle (CT) e emR03, sendo os menores valores encontrados em R15 eDS.A área desmatada, por não possuir vegetação, apresentou os menores valores de $\mathrm{MO}$, sendo que a presença de mais matéria orgânica na área de restauração mais recente é justificada pela lixiviação de nutrientes de R15 corroborando com a tese apresentada por Canellas et al. (2000) e por Silva (2006). Portanto, a análise topográfica é essencial para a interpretação correta da química do solo em virtude dos processos de remoção de nutrientes pela chuva para áreas com menor declividade, sendo importantetambém para o planejamento estratégico dos processos de restauração florestal. Os estudos de Capoane, Tiecher e Santos (2017) também apontam para o mesmo padrão ao associar em análises de topossequência maiores teores de carbono e fósforo na baixada das encostas, seguido da base, topo e meia encosta. Para os autores a movimentação de sedimentos é controlada pela posição, forma e declividade da encosta, sendo que a condição hidromórfica do solo contribui para acumulação de matéria orgânica e para a solubilização de óxidos de ferro e alumínio.

Com relação à capacidade de troca catiônica a área controle registrou os melhores índices, seguidos por R15, R03 e DS, respectivamente. Em solos tropicais ácidos, a matéria orgânica exerce uma importante função no que diz respeito à disponibilidade de nutrientes, pois a maior parte da CTC destes solos é proveniente dos coloides orgânicos (MALAVOLTA, 1993). Esta também apresenta relações com demais propriedades físicas, 
químicas e biológicas do solo (SANTOS et al., 2008). Segundo Prado (2003) a importância da CTC refere-se não tão somente à retenção de cátions, mas também de água, além de ter relação direta com a estruturação e consistência dos solos.

O cálcio encontrado na área restaurada $(\mathrm{R} 15)$ e desmatada pode ser considerado baixo, sendo alto apenas em CT e médio em R03. Com relação à concentração de Magnésio R15 e R03 apresentaram valores médios e CT valores acima de 0,9 cmolc. $\mathrm{dm}^{-3}$, sendo considerada uma faixa muito boa deste elemento, de acordo com Alvarez (1999).

O fósforo na área sem cobertura vegetal demonstrou ser uma das mais baixas quantidades verificadas entre as áreas estudadas. As demais áreas apresentaram valores entre 7,3 a $8,6 \mathrm{mg} \mathrm{dm}^{-3}$, sendo o ponto de controle de florestaa que apresentou maior taxa desse parâmetro.

No que se refere ao parâmetro potássio DS constatou-se baixos índices do elemento, com valores inferiores a $100 \mathrm{mg} \cdot \mathrm{dm}^{-3}$, sendo que valores superiores a $200 \mathrm{mg} \cdot \mathrm{dm}^{-3}$ foram encontrados em CTe valores médiosde 140 mg.dm³identificados em R15 e R03.

O alumínio do solo esteve mais elevado em DS e em R15, sendo que os menores valores foram encontrados em CT e em R03, cabendo destacar que os elevados índices de alumínio encontrados em DS e R15são justificados pelo revolvimento do horizonte B da área desmatada pela mineração e pelos processos de lixiviação, respectivamente.

A soma de bases na área restaurada $(R 15)$ e desmatada ficaram abaixo de 1,7 cmolc. $\mathrm{dm}^{-3}$, sendo que R03 apresentou valores medianos e a área controle encontrou-se na faixa considerada muito boa com valores superiores a 3,6 $\mathrm{cmolc}^{-\mathrm{dm}^{-3}}$ desse parâmetro. $A$ saturação de alumínio permitiu verificar que a área desmatada com horizonte $B$ exposto foi a área com maior saturação por alumínio seguida por uma saturação média em R15. Tanto em R03 quanto em CT os índices de saturação foram menores que 30\%.

No que se refere à saturação por bases, R15, DS e R03 apresentaram valores menores que $40 \%$, sendo que somente CT exibiu valores de médio a muito bom com percentual superior a $60 \%$.

De um modo geral as análises do complexo sortivo do solo revelou que a área controle foi a área que obteve os melhores indicadores de fertilidade, sendo que a área desmatada obteve os piores índices, fato este esperado pelas características das respectivas áreas. As áreas restauradas (R15 e R03) foram as mais importantes para se avaliar o sucesso da restauração florestal, tendo como base os parâmetros das áreas de controle de mata nativa e sem cobertura vegetal. Destacou-se como fato importante a ser considerado nas áreas restauradas a análise da influência topográfica uma vez que áreas próximas podem sofrer influências dos processos de lixiviação, causando a remoção de nutrientes para áreas adjacentes a jusante como é o caso de R03 (conforme demostrado no perfil topográfico da 
Figura 3). Assim, essa conjuntura justifica que alguns parâmetros de qualidade foram maiores em R03 (matéria orgânica, cálcio, magnésio, fosforo e $\mathrm{pH}$ ) do que em R15, tendo em vista que R03possui cobertura arbórea inferior a 1,5 metro e com pouca produção de serapilheira quando comparada à área restaurada de 15 anos. Neste contexto, a área de restauração recente apresentou condições favoráveis em longo prazo para o sucesso da restauração florestal no que se refere ao substrato, pois a sua posição na baixa encosta favorece o acúmulo de nutrientes e umidade. Em uma área de reflorestamento, segundo Chada, Campello e Faria (2004), a sucessão vegetal evolui mais rapidamente nas menores declividades pelos mesmos motivos supracitados.

\section{Análise Micromorfológica}

De acordo com o primeiro mosaico de lâminas (Figura 5) da área restaurada (R15) observa-se a presença de esqueleto formado por grãos de quartzo e matriz escura, o que indica a presença de um plasma influenciado pela presença de matéria orgânica. Também foram identificados agregados circulares (identificados nas figuras com círculo em amarelo), que podem ser decorrentes da ação da macrofauna do solo. Foi observado também a presença de porosidade mais aberta, poros fissurais, além da presença de raízes demonstradas na figura (5-F2).

Durante a coleta das amostras foram observados cropólitos (Figura 6) que podem corresponder a parte das estruturas arredondas encontradas nas lâminas de R15.Esses organismos verificados em campo e que realizam bioturbação são chamados de "engenheiros do ecossistema" (ALVES et al., 2014) ou "engenheiros do solo" (KORASAKI; MORAIS; BRAGA, 2013), sendo os principais representantes desse grupo as minhocas, as formigas e os besouros (KORASAKI; MORAIS; BRAGA, 2013; SWIFT et al., 2010). Esta denominação de engenheiros do solo se deve ao fato dos horizontes do solo serem repletos de excrementos da macrofauna, demonstrando a importância desses organismos na movimentação, formação de poros e na transformação de materiais orgânicos no solo (DAVIDSON; GRIEVE, 2006).

A figura 7 demonstra os mosaicos de lâminas de R03, onde novamente é observado a presença de agregados circulares (F1-F2-F3) e a presença de raízes (F1-F2-F5) associado a um esqueleto mais grosseiro e a uma porosidade aberta.

De acordo com o mosaico de lâminas de CT (área controle) (Figura 8) verifica-se a presença de porosidade cavitária e de canais sem a presença de agregados circulares como as lâminas anteriores, havendo, porém, um esqueleto com material mais selecionado. Analisando as lâminas como um todo, todas apresentaram porosidade entre $60 \%$ e $70 \%$ em termos totais da lâmina. 
Figura 5 - Mosaico de fotos de lâminas micromorfológicas de R15

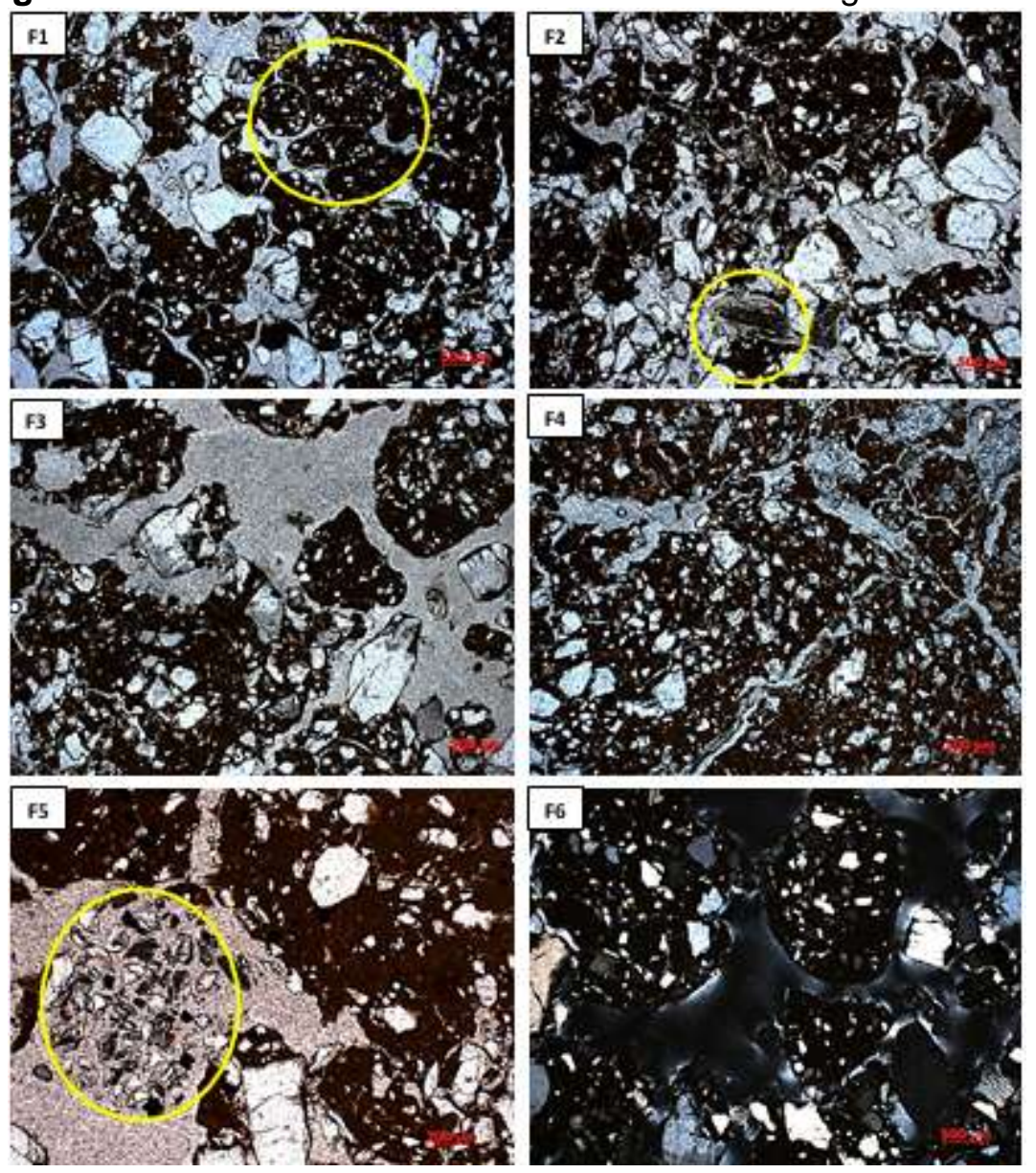

Fonte: elaborada pelos autores. Legenda: F1 - São observados agregados circulares com material mais fino no interior, sendo indicativos de atividade biológica; F2- Destaca-se a presença de raízes; F3 e F4- Verifica-se a presença de poros a olho nu e poros fissurais na lâmina; F5- Ampliação em objetiva de 5x mostrando agregados circulares (material selecionado e orientado no centro). F6fotografia em luz polarizada demonstrando porosidade aberta e ressaltando os agregados.

Figura 6 - Coprólitos de Larva de Besouro

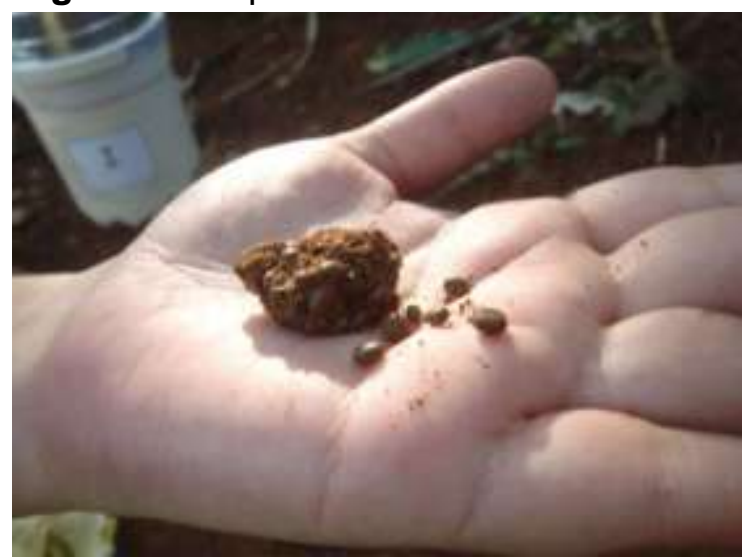

Fonte: elaborada pelos autores. 
Figura 7 - Mosaico de fotos de lâminas micromorfológicas de R03
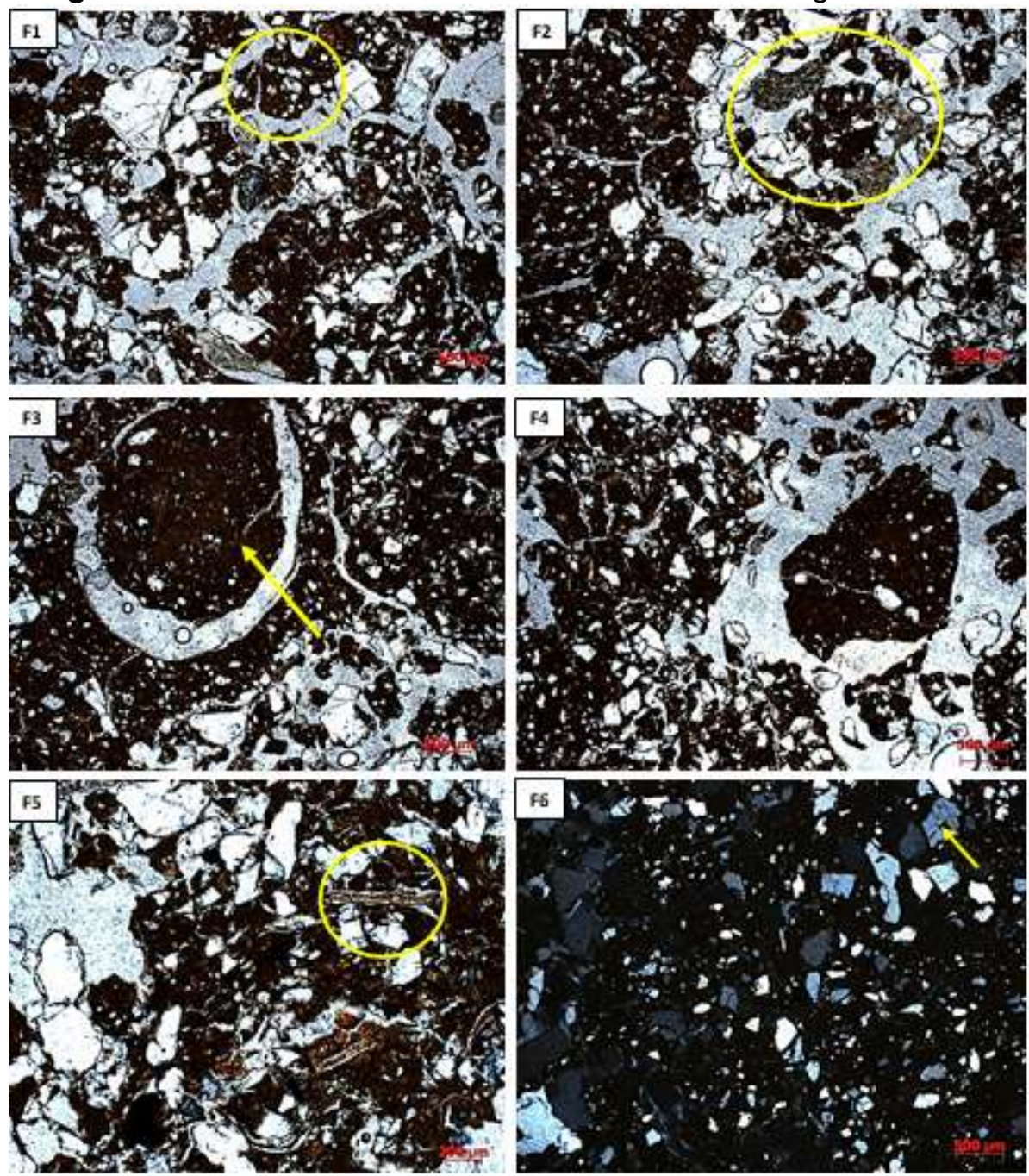

Fonte: elaborada pelos autores. Legenda: F1: São observados agregados circulares com material; mais fino no interior, sendo indicativos de atividade biológica; F2- Destaca-se a presença de raízes e organizações circulares; F3 - Observado organizações circulares com material mais fino no interior (indicado na seta) sendo indicativos de atividade biológica; F4- Verifica-se a presença de porosidade aberta; F5- Ampliação em objetiva de 5x destacando raízes F6- Fotografia em luz polarizada demonstrando a presença de quartzos e de quartzo mais intemperizado que os demais do entorno conforme sinalizado pela seta.

As lâminas de solo apenas refletem uma fração dos processos que ocorrem nos solos analisados, sendo que os resultados demonstraram o predomínio da macroporosidade e da atividade da mesofauna que possibilita a criação de canais e galerias que são importantes para o crescimento radicular das raízes e para o acesso a nutrientes, significando, portanto, conjuntura favorável ao crescimento vegetal nas três áreas analisadas. 
Figura 8 - Mosaico de Lâminas micromorfológicas em CT
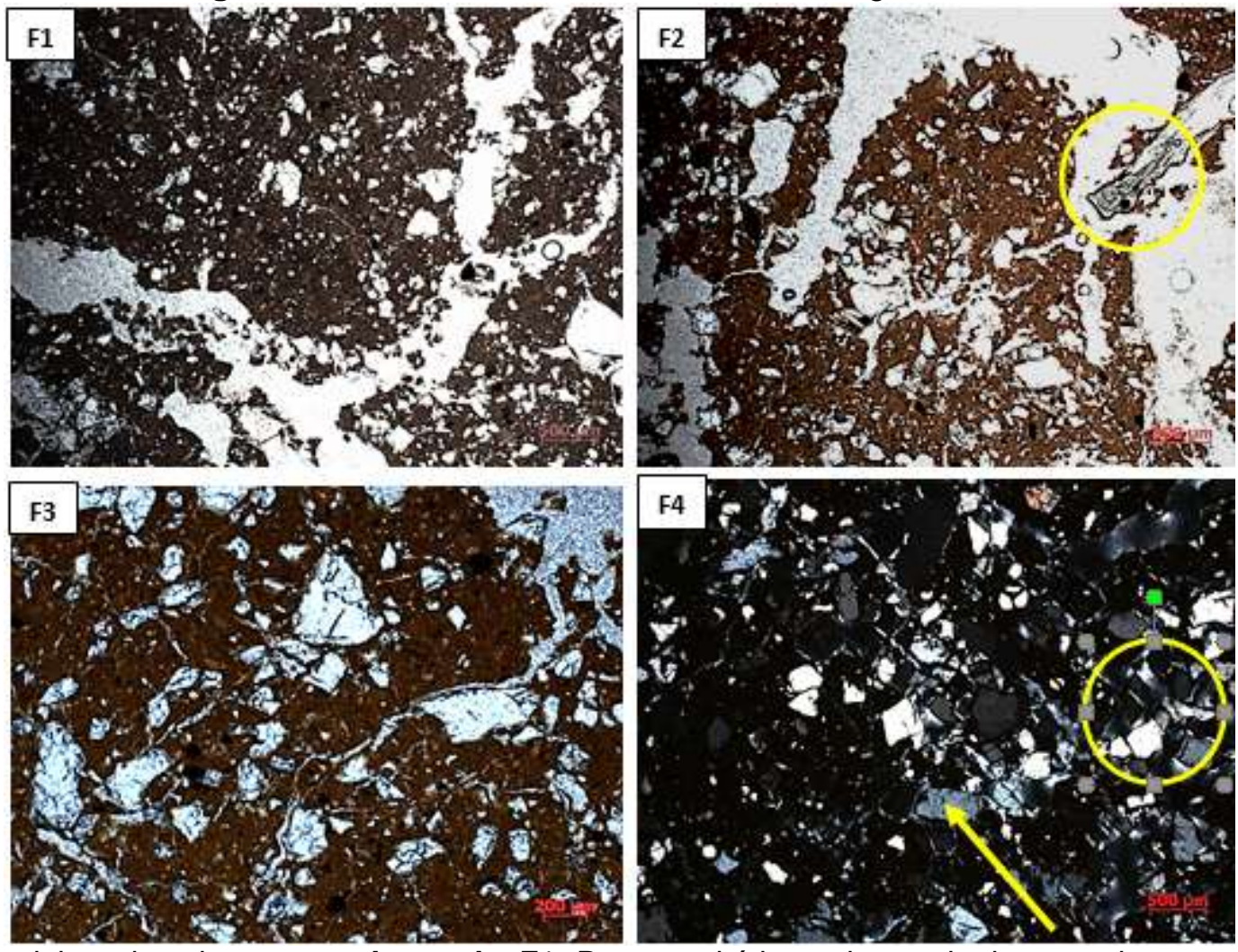

Fonte: elaborada pelos autores. Legenda: F1- Poros cavitários e de canais destacando-se em trama fina; F2- Porosidade aberta e destaque em círculo amarelo de uma raiz; F3- Ampliação em objetiva de $5 x$ demonstrando uma matriz fina e alguns grãos de quartzo maiores. F4- Fotografia em luz polarizada destacando a presença de minerais de quartzo bem selecionados na porção indicada pelo círculo e mais intemperizado conforme indicado pela seta.

\section{Indicadores biológicos: bactérias e fungos do solo}

De acordo com os dados da Tabela 2, que sintetiza as informações da contagem de fungos e bactérias das áreas de estudo, verifica-se que a área restaurada de 15 anos apresentou as maiores contagens de bactérias e fungos em um grama de solo.

Tabela 2 - Contagem de bactérias e fungos por área de monitoramento

\begin{tabular}{ccc}
\hline \multicolumn{1}{l}{ Áreas } & Bactérias $\left(\mathbf{x ~ 1 0 ^ { 4 }}\right)$ & Fungos $\left.\mathbf{( x ~ 1 0 ^ { 2 }}\right)$ \\
\hline R15 (Restaurada 15 anos) & 27.04 & 330.50 \\
\hline DS (Desmatada) & 24.60 & 39.97 \\
\hline R03(Restaurada 03 anos) & 21.63 & 247.20 \\
\hline CT(Controle) & 6.79 & 217.40
\end{tabular}

Fonte: elaborada pelos autores.

A área desmatada apresentou a segunda maior contagem de bactérias, associadas a uma menor comunidade de fungos, fato este relacionado a pouca umidade e a elevadas temperaturas da área que não proporcionam condições favoráveis ao crescimento deste tipo de microrganismo (MOREIRA et al., 2013). A área R03 apresentou o terceiro maior número 
de bactérias e a segunda maior taxa de fungos. A área controle destacou-se pela reduzida contagem de bactérias e pela segunda menor taxa de fungos, não significando, porém, menor diversidade.

Segundo Grayston et al. (2001) um solo com elevado teor de matéria orgânica tende a manter a população microbiana mais estável, em decorrência da riqueza de nichos ecológicos, pelas diversificadas fontes de carbono e pela diminuição da dominância de espécies, justificando, portanto, os menores registros de bactérias e fungos na área controle. Assim sendo, estes resultados demonstram que R15 e R03 ainda não alcançaram maior estabilidade de seus parâmetros químicos, sobretudo no que se refere à matéria orgânica para que ocorra maior estabilidade da comunidade microbiana como fora alçado pela área controle em estágio médio de sucessão ecológica.

\section{CONCLUSÃO}

De acordo com a análise dos pedoindicadores, verificou-se que os parâmetros químicos selecionados podem ser utilizados para avaliar as mudanças que acontecem no substrato, refletindo assim a sua influência no crescimento das plantas e, portanto, na taxa de sucesso da restauração florestal. Neste sentido, verificou-se que da forma esperada a área controle obteve os melhores pedoindicadores, assim como a área desmatada obteve os índices mais negativos. Contudo a área R15 e R03 obtiveram respostas diferenciadas, sobretudo no que se refere aos parâmetros químicos, pois vários deles, como o pH, fósforo, cálcio, magnésio, soma de bases, saturação por bases e matéria orgânica foram mais adequados em R03 que na área restaurada de 15 anos, sendo tal fato associado à lixiviação que ocorre em R15 e a consequente acumulação de nutrientes nas áreas de menor declividade, ressaltando, portanto, a importância da análise integrada da paisagem inclusive do ponto de vista estratégico para seleção de áreas prioritárias à restauração florestal,de acordo coma topografia mais favorável à restauração.

A análise micromorfológica e a contagem de bactérias e fungos demonstraram ser úteis num contexto de demais informações das áreas selecionadas, podendo ser utilizadas como suporte para a interpretação da evolução biológica das áreas em restauração e sendo reflexo também das condições químicas e físicas do substrato e da cobertura vegetal. Conclui-se que através da análise micromorfológica é possível acompanhar a evolução e a influência da atividade biológica nos solos, sendo que esta indicou a ação da fauna edáfica através da presença de coprólitos e bioturbações nas lâminas. Já a contagem de bactérias e fungos demonstrou que ambas as áreas restauradas ainda necessitam estabilizar o número das comunidades microbianas (fungos e bactérias), fato este que está interligado a uma 
melhora dos parâmetros químicos do solo conforme foi ressaltado nos dados obtidos na área controle.

Desta forma destaca-se que as áreas em processo de restauração (R15 e R03) ainda não são semelhantes à área de referência em quase todos os parâmetros analisados nas respectivas fases do processo de restauração em que estas se encontram, possuindo, porém, condições favoráveis para tal a longo prazo, sobretudo em R03.

As análises comparativas entre diferentes tipos de cobertura foram essenciais para avaliação do progresso do processo de restauração florestal, sendo que a restauração das áreas de mineração e de outras áreas degradadas no município possui uma importância estratégica para a reconexão dos fragmentos florestais, que podem viabilizar a recuperação da biodiversidade através da implantação de corredores biológicos e permitindo que o bioma Mata Atlântica se mantenha como um dos conjuntos de ecossistemas mais biodiversos do planeta.

\section{REFERÊNCIAS}

ALMEIDA, Raquel Olimpia Peláez; SANCHEZ, Luiz Henrique. Indicadores de qualidade do substrato para o monitoramento de áreas de mineração revegetadas. Floresta e Ambiente, Seropédica, v. 22, n. 2, p. 153-163, 2015.

ALVAREZ. Victor Hugo et al. Interpretação dos resultados das análises de solo. In: RIBEIRO, Antonio Carlos; GUIMARÃES, Paulo Tácito; ALVAREZ, Victor Hugo (ed.). Recomendação para o uso de corretivos e fertilizantes em Minas Gerais: $5^{\text {a }}$ aproximação. Viçosa: Comissão de Fertilidade do Solo do Estado de Minas Gerais, 1999. p. 31-36.

ALVES, Francisco Abel Lemos et al. Caracterização da macro e mesofauna edáfica sobre um fragmento remanescente de "mata atlântica" em Areia PB. Gaia Scientia, [s. I.]. v. 8, n. 1, p. 384-391, 2014.

BRANCALION, Pedro Henrique Santin; GANDOLFI, Sergius; RODRIGUES, Ricardo Ribeiro. Incorporação do conceito da diversidade genética na restauração ecológica. In:

RODRIGUES, Ricardo Ribeiro; BRANCALION, Pedro Henrique Santin; ISERNHAGEN, Ingo. Pacto para a restauração ecológica da Mata Atlântica: referencial dos conceitos e ações de restauração florestal. São Paulo: Instituto BioAtlântica, 2009. p. 37-54.

BRANCALION, Pedro Henrique Santin; GANDOLFI, Sergius; RODRIGUES, Ricardo Ribeiro. Restauração florestal. São Paulo: Oficina de Textos, 2015.

BRANDÃO, Cássia Barreto et al. Determinação do perfil climatológico do Município de Santo Antônio de Pádua-RJ e sua aplicabilidade na recuperação de áreas degradadas. Anuário do Instituto de Geociências, Rio de Janeiro, v. 39, n. 1, p. 5-12, 2016.

BRASIL, Lucas Santa Cruz de Assis; SILVA, Antônio Soares. Mapeamento da cobertura vegetal e do uso do solo no Município de Santo Antônio de Pádua-RJ. In: UERJ SEM MUROS, 23., 2013, Rio de Janeiro. Anais [...]. Rio de Janeiro: UERJ, p 1-16, 2013. 
BREWER, Roy. Fabric and mineral analysis of soils. New York: Krieger, 1976.

BULLOCK, Peter et al. Handbook for soil thin section description. Wolverhampton: Waine Research Publication, 1985.

BRUM, Irineu Antônio Schadach. Recuperação de áreas degradadas pela mineração. 2000. Monografia (Especialização em Gerenciamento e Tecnologias Ambientais na Indústria) - Departamento de Hidráulica e Saneamento, Escola Politécnica, Universidade de São Paulo, São Paulo, 2000.

CHADA, Sylvia de Souza; CAMPELLO, Eduardo Francia Carneiro; FARIA, Sérgio Miana. Sucessão vegetal em uma encosta reflorestada com leguminosas arbóreas em Angra dos Reis, RJ. Revista Árvore, Viçosa, v. 28 n.6, p. 801-809, 2004.

CANELLAS, Luciano Pasqualoto et al. Frações da matéria orgânica em seis solos de uma topossequência no Estado do Rio de Janeiro. Pesquisa Agropecuária Brasileira, Brasília, v. 35, n.1, p.133-143, 2000.

CAPOANE, Viviane; TIECHER, Tales; SANTOS, Danilo Rheinheimer. Variação de atributos do solo ao longo de três topossequências no planalto do Rio Grande do Sul. Revista Brasileira de Geografia Física, Recife, v.10, n. 5, p. 1435-1454, 2017.

COSTA, Gabriel Campos Pereira; SILVA, Antonio Soares. Aumento da erosão pela compactação do horizonte superficial causada pelo pisoteio bovino em Santo Antônio de Pádua - RJ. In: $15^{\circ}$ CONGRESSO BRASILEIRO DE GEOLOGIA DE ENGENHARIA E AMBIENTAL, 15., 2015, Bento Gonçalves. Anais [...]. São Paulo: ABGE, 2015. p. 1-10.

DANTAS, Marcelo Eduardo et al. Diagnóstico geoambiental do estado do Rio de Janeiro - estudo geoambiental do estado do Rio de Janeiro. Brasília, DF: CPRM-DEGET, 2001.

DAVIDSON, Donald; GRIEVE, lan. Relationships between biodiversity and soil structure and function: evidence from laboratory and field experiments. Applied Soil Ecology,

Amsterdam, v. 33, n. 2, p.176-185, 2006.

FUNDAÇÃO SOS MATA ATLÂNTICA. Atlas dos remanescentes florestais e ecossistemas associados da Mata Atlântica no período de 2016-2017. São Paulo: INPE, 2019. Disponível em: http: www.sosmatatlantica.org.br. Acesso em: 14 set. 2019.

GRAYSTON, Sue et al. Accounting of variability in soil microbial communities of temperate upland grassland ecosystem. Soil Biology and Biochemistry, Elmsford, v. 33, n. 4/5), p. 533-551, 2001.

IBGE. Censo 2010. Disponível em: https://censo2010.ibge.gov.br/. Acesso em: 05 ago. 2020.

IBGE. Geografia do Brasil. Rio de Janeiro: IBGE, 1977.

JAHNEL, Marcelo Cabral; CARDOSO, Elke Jurandy Bran Nogueira; DIAS, Carlos Tadeu. Determinação do número mais provável de micro-organismos do solo pelo método de plaqueamento por gotas. Revista Brasileira de Ciências do Solo, [Visoça], v. 23, n. 3, p. 553-559, 1999.

KORASAKI, Vanesca; MORAIS, José Wellington; BRAGA, Rodrigo. Macrofauna. In: MOREIRA. Fátima Maria de Souza et al. (ed.). O ecossistema solo: componentes, relações ecológicas e efeitos na produção vegetal. Lavras: UFLA, 2013. p. 79-128.

LAMEGO, Alberto Ribeiro. O Homem e a Serra. Rio de Janeiro: IBGE, 1963. 
LEPSCH, Igor Fernando.19 lições de Pedologia. São Paulo: Oficina de textos, 2011. MALAVOLTA, Eurípedes. Nutrição mineral e adubação do cafeeiro: colheitas econômicas máximas. São Paulo: Agronômica Ceres, 1993.

MOREIRA, Fátima Maria de Souza et al. O ecossistema solo: componentes, relações ecológicas e efeitos na produção vegetal. Lavras: UFLA, 2013.

PRADO, Hélio. Solos do Brasil: gênese, morfologia, classificação, levantamento, manejo agrícola e geotécnico. Piracicaba: USP, 2003.

RAIJ, Bernardo Van. Fertilidade do solo e manejo de nutrientes. Piracicaba: International Plant Nutrition Institute, 2017.

RODRIGUES, Efraim. Ecologia da restauração. Londrina: Planta, 2013.

SANTOS, Gabriel et al. Fundamentos da matéria orgânica do solo: ecossistemas tropicais \& subtropicais. Porto Alegre: Metrópole, 2008.

SATTLER, Dietmar et al. Pasture degradation in south east Brazil: status, drivers and options for sustainable land use under climate change. In: LEAL FILHO, Walter; FREITAS, Leonardo Esteves(Org.). Climate change adaptation in Latin America. Cham: Springer, 2017. v. 1, p. 3-17.

SELIGER, Roman et al. Rehabilitation of degraded sloped pastures: lessons learned in Itaocara, Rio de Janeiro. In: NEHREN, Udo et al. (org.). Strategies and tools for a sustainable rural Rio de Janeiro. Rio de Janeiro: Springer, 2018, v. 1. p. 391-404.

SILVA, Antonio Soares. Influência da erosão remoção de nutrientes e metais pesados em uma topossequência em Petrópolis (RJ). 2006. Tese (Doutorado) - Universidade Federal do Rio de Janeiro, 2006.

SILVA, Antonio Soares. Mineração e áreas de preservação permanentes (APPs) em Santo Antônio de Pádua - RJ. Sociedade e Natureza, Uberlândia, v. 23, n. 2, p.173-185, 2011.

SILVA, Rosana Elisa Coppedê; MARGUERON, Cláudio. Estudo Geológico-Técnico de uma pedreira de rocha ornamental no município de Santo Antônio de Pádua - Rio de Janeiro. Anuário do Instituto de Geociências, Rio de Janeiro, v. 25, p. 125-150, 2002.

SOCIETY FOR ECOLOGICAL RESTORATION INTERNATIONAL SCIENCE \& POLICY WORKING GROUP. The SER International Primer on Ecological Restoration. 2004. Disponível em:

https://cdn.ymaws.com/www.ser.org/resource/resmgr/custompages/publications/ser_publicat ions/ser_primer.pdf. Acesso em: 14 nov. 2020.

SWIFT, Mike et al. O inventário da biodiversidade biológica do solo: conceitos e orientações gerais. In: MOREIRA, Fátima Maria de Souza; HUISING, Jeroen; BIGNELL, David (ed.).

Manual de biologia dos solos tropicais: amostragem e caracterização da biodiversidade. Lavras: UFLA, 2010. p. 23-41.

TEIXEIRA, Paulo César et al. Manual de métodos de análise de solo. Brasília, DF: Embrapa, 2017. 


\section{AGRADECIMENTOS}

Ao CNPq pelo financiamento do Projeto: Recuperação e reabilitação de áreas degradadas por mineração na zona rural de Santo Antônio de Pádua (RJ), processo 561869/2010-3. A CAPES pela concessão de bolsa de Pós-Graduação em nível de Doutorado à primeira autora.

Recebido: outubro de 2020. Aceito: março de 2021. 